\title{
Perceptions of the corporate identity management process in South Africa
}

\author{
G. Bick \\ Wits Business School, University of the Witwatersrand, \\ PO Box 98, Wits 2050, Republic of South Africa \\ geoff.bick@wits.ac.za \\ R. Abratt* \\ Wits Business School, University of the Witwatersrand, and \\ Nova Southeastern University, 3301 College Avenue, Ft. Lauderdale, F1 33314, USA, \\ abratt@huizenga nova.edu \\ A. Bergman \\ Wits Business School, University of the Witwatersrand, \\ PO Box 98, Wits 2050, Republic of South Africa
}

Received May 2008

\begin{abstract}
This article reports on a qualitative study of how the corporate identity management process is perceived and managed by senior executives in large South African companies. The concepts of identity, corporate reputation, corporate branding, and the corporate identity management process are discussed. It is suggested that these concepts create confusion among executives and academics and therefore the image and reputation of a company may be affected. Results are reported from an in-depth study of 14 senior managers and directors from 8 large companies. Key recommendations are made and a step-by-step guide is given on how to develop an effective and successful corporate identity, leading to a good reputation in the long term.
\end{abstract}

*To whom all correspondence should be addressed.

\section{Introduction}

Corporate identity (CI) is a concept that deals with what managers want to communicate about their organization, or "what I say about myself". The concept of corporate identity dates back to the 1960's and much work has been done since then in the literature (He \& Balmer, 2007). This leads to different stakeholders having specific images about a firm. This in turn influences the reputation of the firm over a long period of time. Thus, just as firms compete for customers, they compete for reputational status as well (Fombrun \& Shanley, 1990). All this could be thought of as the corporate brand. CI provides the foundation for other concepts such as corporate branding, corporate image and reputation (He \& Balmer, 2007). Unfortunately, there is a lot of confusion amongst both practitioners as well as academics as to what the various terms mean. In addition, how to develop and implement the Corporate Identity Management (CIM) process is also subject to debate. While previous research has focused mainly on describing the CIM process conceptually through models, the purpose of this study is to gain an understanding of how the management of some selected South African companies perceives the CIM process and how corporate identity is managed.

\section{The concepts}

Identity

Several different terminologies for and interpretations of identity exist in the literature. Some of the concepts used are organisational identity, corporate identity, visual identity, business identity and brand identity. Organisational identity appears to be most commonly used among organisational and management researchers, while corporate identity is more frequently used in the marketing literature (Hatch \& Schultz, 1997). Interpretations of them appear to approximate each other more in recent literature. (He \& Balmer, 2007; Van Riel \& Balmer, 1997). According to Albert and Whetten (1985) organisational identity is the collective perception that an organisation's members have about their organisation. The concept of corporate identity is often used in the marketing literature. However, there are several different views on how to define and interpret the concept of corporate identity. To clarify the different interpretations, Van Riel and Balmer (1997) have divided different researchers' views into three different paradigms: The first paradigm is "the graphic design paradigm". Van Riel and Balmer (1997, 340) argue: "Originally, corporate identity was synonymous with organizational nomenclature, logo, company house style and visual identifications.” The authors claim that it was graphic design consultants who 
started to refer to the concept. The second paradigm is, according to Van Riel and Balmer (1997:341) "the integrated communication paradigm”, which derives from marketers and graphic designers who started to advocate consistency in all formal corporate communications, not only in graphic design. Bernstein (1986) was one of the predecessors who argued that corporate consistency in communication to all stakeholders, not only customers, is important for a corporation's effectiveness. The third paradigm, "the interdisciplinary paradigm" gives an even broader view of what corporate identity means and includes behaviour, communications and symbolism expressed externally as well as internally (Van Riel \& Balmer, 1997:341). Cunnington $(1996,61)$ gives examples of what identity could be: "To say that an organization is a 'marketoriented company' is to ascribe a particular identity to the organization. The same is true when the statement 'this is a learning organization' is being made.”

Carroll (2002:558) argues that corporate identity may be viewed as a "sustainable story" that is "...unique to the organisation that originates it and is not imitable by others." Gioia (2000:67) does not agree on identity being stable since "Image often acts as a destabilising force on identity, frequently requiring members to revisit and reconstruct their organizational sense of self.” Thus we can say that corporate identity can be defined as the reality and uniqueness of an organisation which is integrally related to its external and internal image and reputation through corporate communication (Berrone, Surroca \& Tribo, 2007).

\section{Image}

The definition and conceptualisation of image has also been a highlighted and debated subject within the literature of several disciplines, including marketing and organisational behaviour. Barich and Kotler (1991:95) define image as "...the sum of beliefs, attitudes and impressions that a person or a group has of an object. The object may be a company, product, brand, place or person." The same authors further define corporate image as "the way people view the whole corporation” (Barich \& Kotler, 1991:95). Gioia (2000) differentiates between image as an internal concept and as an external concept. The internal conception is the perception that internal members have of the organisation. It could either mean how the employees believe that external stakeholders perceive the organisation or in a more visionary sense, how the employees would prefer external stakeholders to perceive the organisation. The external approach of image is, according to Gioia (2000), the external stakeholders' actual view of the organisation. Thus, it is the interaction or an experience with a corporate identity is what produces a corporate image in the minds of the public (Bendixen \& Abratt, 2007).

\section{Corporate reputation}

According to Gioia (2000:p.66) corporate reputation is “...the collective judgements (by outsiders) of an organization's actions and achievements." It is a "company centric" concept that focuses on the credibility and respect that an organisation has among a broad set of constituencies (Ettenson \& Knowles, 2008). Gioia (2000) argues that reputation is a long lasting, cumulative and global assessment rendered over a long time, while image represents transient impressions that concern more limited events and shorter periods. Balmer (2001:273) gives a similar definition of corporate reputation: “...the enduring perception held of an organisation, by an individual, group or network." To further clarify the concept, Balmer (2001:273) explains that the key question addressed for corporate reputation is: "What distinctive attributes (if any) are assigned to the organisation?" The key question addressed for corporate image is: "What is the current perception and/or profile?” (Balmer, 2001:273). Dowling (1986) has identified the following six variables that affect corporate reputations: the company vision, the formal company policies, the organisational culture, communications, corporate identity and images of the brand, the country and/or the industry that a certain company is doing business within.

\section{Corporate branding}

Bick, Jacobson and Abratt (2003:842) define corporate branding as: “...a manifestation of the features that distinguish an organisation from its competitors. The corporate brand defines the firm that will deliver and stand behind the offering that the customer will buy and use (Aaker, 2004). It is a reflection of the organisation's ability to satisfy consumer's needs, namely: trust in the company to deliver a consistent level of product/service, quality of the product/service at a reasonable price and reduction of risk of making an unwise purchase decision." According to Ettenson and Knowles (2008), corporate brand is a "customer centric" concept that focuses on what a product, service or company has promised its customers. Corporate brands can increase the company's visibility, recognition and reputation since they are not only positioned to customers, which product brands normally are (Hatch \& Schultz, 2003). Bickerton (2000) argues that corporate branding must both assist in the shaping of an organisation's values and culture and be a strategic management tool for value creation for all of the company's stakeholders, including employees, customers, investors, suppliers, partners, regulators, etc. This requires continuity throughout the organisation and consistency in relations with all the different stakeholders, according to Bickerton (2000).

Bick et al. (2003:836) agree on the importance of top management's role when building a corporate brand: "What became abundantly clear was that the $21^{\text {st }}$ century corporate brand management would, by necessity, occupy more of the chief executive's time if his/her company was to survive in the global marketplace." Hatch and Schultz (2003) argue that the strategic importance of corporate branding lies not exclusively in the positioning of the company in its marketplace, but also in creating internal arrangements, such as organisational structure, physical design and culture, to support the meaning of the corporate brand.

\section{Proposition development}

Some of the concepts used in the marketing literature are branding, communications, image, identity, reputation, personality and integrated marketing. These concepts may 
be focused on different levels, e.g. product, division or corporate. Balmer (2001) points out that the application of the concepts becomes more complex and strategic at a corporate level than at a product level. Even though many of the concepts have their roots in the marketing literature, Balmer (2001) argues that at a corporate level the concepts should also be linked to corporate strategy, organisational behaviour and human resources. He therefore claims that the traditional marketing department is not capable of managing corporate identity, image and branding issues. Moingeon and Ramanantsoa (1997:384) highlight the difficulty of lack of clarity in conceptualisation and definitions used when describing the CIM process: "Corporate identity can mean many different things, and other phrases (such as corporate image, corporate culture, or corporate personality) can be used by different authors to describe the same concept." According to Balmer (2001) different concepts are used as synonyms or replacement for each other, depending on what concepts are in fashion at the time; scholars have been creating new terms that in reality replace already existing concepts, which confuses the conceptual understanding of CIM; multidisciplinary perspectives on the concepts by scholars from different disciplines have created different starting points and focus; scholars from different academic disciplines have failed to communicate and create an understanding between the disciplines; and different cultures, linguistic groups and geographic areas have created different schools of thought. Identity is explicit, above the surface, textual, and instrumental. Although an organisation can have multiple images, identity is more singular, and, hence, central. None of the three associated constructs corporate image, reputation, and brand - is concerned with traits that are central, distinctive, and enduring, which company identity does. Company identity addresses core characteristics of a company rather than superficial characteristics. Corporate image refers to beholders' immediate and transitory perception of a company, whereas corporate reputation is more stable than corporate image in that it represents a generalised public evaluation and assessment of a company. Company image may be distinctive, but it is rarely central or enduring (Mukherjee \& He, 2008). Reputation may be central but not really enduring or distinctive. Our first proposition therefore is:

\section{P. 1: There is an unclear understanding of the concept of CIM.}

Many authors point out the importance of top management's control and participation of the CIM process: "Those at the strategic apex of an organization must have a clear vision of the identity they wish to create and must be able to translate it into something more practical - an integrated, synergistic operational model - a design that will synergistically fuse strategy, structure and culture into a coherent whole, its configuration design” (Cunnington, 1996:61). “A favourable corporate identity is one of an organization's most important assets and therefore is worthy of constant management attention” (Van Riel \& Balmer, 1997:346). "The actions and statements of top managers simultaneously affect organizational identity and image” (Hatch \& Schultz, 1997:356). Therefore our second proposition is:

\section{P. 2: A CIM process that is initiated and controlled by top management is more likely to become effective.}

Bernstein (1986) was one of the earlier researchers who argued that corporate communication consistency to all stakeholders, not only customers, is important for a corporation's effectiveness. Both Balmer and Gray's (1999) and Bick et al's (2003) models are based on integrated marketing communication. Bick et al. (2003) highlight the importance of building up internal structures and systems that stimulate consistent messages in accordance with the strategy that is communicated to all the company's stakeholders. Bickerton (2000) argues that corporate branding must both assist in the shaping of an organisation's values and culture and be a strategic management tool for value creation to all of the company's stakeholders, including employees, customers, investors, suppliers, partners, regulators, etc. This requires continuity throughout the organisation and consistency to all the different stakeholders. Bick et al. (2003:850) argue that their "model highlights the importance of integrating all the management disciplines in the communication process so that employees can absorb and accept the desired norms and values of senior management." Hatch and Schultz (2003:1043) argue that: "The strategic importance of corporate branding lies not only in its positioning of the company in its marketplace, but in creating internal arrangements (e.g. organisational structure, physical design and culture) that support the meaning of the corporate brand.” Bickerton (2000) argues that to reach brand consistency and continuity, a unique organisation value proposition (UOVP) must be formulated. The UOVP should consist of a visible set of credentials that integrate the organisation's core business processes - e.g. supply partnership, asset management, resource transformation, customer development, marketing planning and the higher marketing mix variables of the brand that bind the core processes together. We posit our third proposition as follows:

$P$ 3: A CIM process that is integrated within the whole organisation and strives for consistency in communications with and behaviour towards the stakeholders is more likely to become effective.

Bick et al's (2003) model shows that the identity management process should be an adaptive process. They claim that strategy is emergent and should constantly adapt to changes in the external environment. Van Riel and Balmer (1997) argue that organisational behaviour and corporate communication need a constant evaluation. Barich and Kotler (1991) suggest that companies should have an image-tracking system, so that changes in images and perceptions of weak performance may be controlled over at an early stage. He and Balmer (2007) found an explicit overlap between CI and organisational identity. The emerging synergy between marketing and organisational behaviour in terms of identity studies might consolidate identity studies into an emerging area of study: corporatelevel marketing. The fourth proposition is: 
P 4: A CIM process that is adaptive is more likely to become effective.

The literature stresses the marketing and economic benefits of CI in terms of positioning and competitive advantage (He \& Balmer, 2007). Van Riel and Balmer (1997:342) argue: "The objective of CIM is to establish a favourable reputation with an organization's stakeholders which is hoped will be translated by such stakeholders into a propensity to buy that organization's products and services, to work for or to invest in the organization.” Bick et al.'s (2003:851) model shows that an organisation's strategy formulation and implementation lead to a corporate identity - "What the organisation is" - through its behaviour towards and communication with the stakeholders. The projected images influence the corporate image - "Momentary views of the organisation" among the different stakeholders. The stakeholders may view these images as positive or negative and the views may be consistent or inconsistent. The collection of all the images builds up the corporate reputation - "Long-term views of the organisation". A positive corporate reputation is a requirement for competitive advantage and the creation of a strong corporate brand (Fombrun \& Van Riel, 2004). Our last proposition is:

\section{P 5: A CIM process increases a company's competitiveness.}

\section{Methodology}

Since the purpose of the research was to identify the subjective views of individual managers' perceptions, actions and behaviours, the study is based on qualitative research methods. Falconer and Mackay (1999:69) state: "Qualitative researchers study things in their natural settings, attempting to make sense of, or interpret, phenomena in terms of the meaning people bring to them.”

\section{Population and sample}

The empirical study focuses on medium-sized to large companies within the service and retail sectors that target the consumer market. Only companies operating in South Africa have been selected. All the chosen companies are successful within their businesses and have strong and wellknown corporate brands within their target markets. The aim was to learn from them how CIM practically works in some successful companies and how the managers of those companies think and act regarding CIM. The choice of which companies to contact was based on convenience sampling.

A short email that described the purpose of the research and introduced the researchers' and the interview proposal was sent to the selected interview prospects. After two to three days, those interview prospects were contacted by a phone call. On acceptance, the researchers' directly sent an email, to thank the interviewee for participating and confirming the place, date and time of the interview. Each interview took between 45 and 90 minutes to complete. A total of 14 managers and directors from eight companies were interviewed. The companies and the interviewees were guaranteed anonymity.

\section{The companies}

\section{The hotel chain}

The first company is a South African-owned hotel chain with 37 hotels in total situated all over South Africa. Two top management directors were interviewed: the Chief Executive Officer (C.E.O.) and the Human Resources Director (H.R.D.).

\section{The retail conglomerate}

The second company is a retail group of nine different retail brands with over 700 retail stores situated in Southern Africa. The Project Manager of Strategic Initiatives (P.M.S.I.) was interviewed. The interviewee is operationally responsible for the progress of the projects involving CIM. She is not part of the top management team but she reports directly to the C.E.O.

\section{The retailer}

The third company is a leading retail company selling food, clothing and general merchandise in Africa. Two employees were interviewed: the Human Resources Director (H.R.D.) and the Identity Manager (I.M.). The H.R.D. is part of the top management team. The I.M. is responsible for corporate communications, which includes formulating centralised policies regarding corporate communications. She reports to the Marketing Director, who is part of the top management team.

\section{The tourism and leisure group}

The fourth company is a tourism and leisure group, comprising 23 hotels and resorts and 17 casinos in Southern Africa. Each of their establishments is an individual concept and brand. Two middle managers were interviewed: The Marketing \& PR Executive of Resorts (M.M.R.) and the Marketing \& PR Executive of Gaming (M.M.G.). The M.M.R reports to the General Manager of Resorts, who in turn reports to the Resort Director who is part of the top management team. The M.M.G. reports to the General Manager of Gaming who in turn reports to the Gaming Director who is part of the top management team.

\section{The retail travel agency}

The fifth company is a foreign-owned global travel retailer, which sells flight tickets and travel packages from its 74 stores nationwide in South Africa. Their global headquarters is situated overseas. The country Human Resources Manager (H.R.M.) and Marketing Manager (M.M.) were interviewed. They report to the country Managing Director, who reports to the global headquarters.

\section{The gym and sports clubs}

The sixth company is a global foreign-owned group of gyms and sport clubs operating nationwide in South Africa. The Marketing Director (M.D.) was interviewed. He is part of the senior management team and reports to the country C.E.O., who in turn reports to the global head quarters. 


\section{The restaurant chain}

The seventh company is a South African-owned restaurant chain operating in 32 countries worldwide. The global Marketing Director (M.D.) and the Human Resources Director (H.R.D.) were interviewed. Both of them are part of the corporate top management team.

\section{The multimedia company}

The last company is a South African pay TV and multimedia broadcasting company operating in 44 African countries. The Human Resources Director (H.R.D.) and the Marketing Director (M.D.) were interviewed. They are both part of the top management team.

\section{Data collection procedures}

A discussion document was developed based largely on the literature review. All the questions were designed to encourage open-ended answers and descriptions by the interviewee. The data collection took place through openended in-depth interviews with managers from the selected companies. The data was safeguarded through the following procedure: Clear, structured, topic-related questions were prepared in advance; The questions were sent to the interviewees electronically at least one week before the interview, so that each interviewee had a chance to prepare and ask questions; A copy of the questions was given to the interviewee just prior to the interview in case he or she had forgotten to bring the questionnaire that had been sent out; The interviewer asked the interviewee for permission to tape record the interview, which permission was granted by all interviewees; The same questions were asked in the same order to all of the interviewees; If the researcher did not understand an answer, the question was redirected to the interviewee; and a summary of the answers from the interview was sent electronically for overview to the interviewee within a week after the interview had taken place.

\section{Data analysis}

The notes were transcribed in a structured way directly after the interviews had taken place, when observations and perceptions were still fresh in the researcher's mind. Each interview transcript was then structured the same way and coded so that further analysis and comparisons between interviews from the same company and interviews from different companies could take place in a cross case analysis. The collected data was clustered to the proposition it related to. The perceptions of the interviewees were structured in clusters, depending on whether they supported or conflicted with the propositions they were intended to answer. The analysis took place through a content analysis and meta-analysis.

\section{Results and discussion}

The findings were analysed in relation to each of the propositions.

\section{Proposition 1: There is an unclear understanding of the concept of CIM.}

Interviewees were required to describe briefly how they defined the concepts of a) corporate identity, b) corporate image and c) corporate identity/image management (CIM). To be able to analyse the results, we clustered together the different definitions of each concept with similar definitions:

a) Corporate identity was defined as: Definition 1: The visual communication of the company. Definition 2: The guiding principles of what the company stands for. Definition 3: Behaviour of the company, Definition 4: Visual communication and staff behaviour. Definition 5: Internal culture. Definition 6: The way a company portrays itself to the market. The findings show that eight of the 14 interviewees associated corporate identity with visual communication, which according to Van Riel and Balmer (1997), was the original definition of corporate identity that was used by graphic designers. According to Moingeon and Ramanantsoa (1997) and Van Riel and Balmer (1997) this definition is too narrow. Three of the interviewees who chose this definition have human resources backgrounds, four are within marketing departments and one is a Chief Executive Officer.

Van Riel and Balmer (1997) suggest a broader view of what corporate identity means, and regard it as including all behaviour, communications and symbolism expressed externally as well as internally. Since behaviour was only mentioned by two of the interviewees (one with a marketing background and one with a Human Resources background) through definitions 2 and 3, it does not appear that the wider definition is commonly used by or associated with the interviewees. Even though organisational behaviour is not commonly associated with the concept of corporate identity, several of the companies put in substantial resources to steer up corporate behaviour, which will be described under proposition 3 .

One of the interviewees, a human resources manager, perceived corporate identity as internal culture. There are different views in the literature of how organisational culture and corporate identity are related. Hatch and Schultz (1997) argue that corporate identity is the outcome of the dynamic processes of organisational culture. Moingeon and Ramanantsoa (1997:385) claim the opposite: "Identity is a conceptual advance over corporate culture because it permits researchers to explain in more depth the dynamics of organizations.” Balmer and Gray (1999) argue that corporate identity includes organisational culture, values and purposes, corporate strategy and the organisational structure.

b) Corporate image was defined as: Definition 1: Stakeholder perceptions, Definition 2: Customer perceptions, Definition 3: How the company is perceived from the outside, Definition 4: What the company stands for, Definition 5: The way a company portrays itself to the market. Twelve of the 14 
interviewees associated corporate image with perceptions of the company through definitions 1 to 3 . Ackerman (1983) and Dowling (1986) distinguish between internal and external image. According to Gioia (2000), corporate image is the perception of all stakeholders, internal as well as external. Eight of the interviewees included all stakeholders in their definitions through their choice of definition 1 . According to Hatch and Schultz (1997), corporate image is an external concept in line with definition 3 , which three of the interviewees mentioned.

c) CIM was defined as: Definition 1: The corporate marketing programme, Definition 2: A process of creating internal behaviour, Definition 3: Management of visual representation and internal behaviour, Definition 4: Management of visual representation, Definition 5: A plan for and the purpose of what the company should do, Definition 6: An ever-evolving process of setting values, Definition 7: Brand management.

The most diverse set of definitions was given here. The interviewees came up with seven different definitions. Five of the 14 interviewees associated CIM with brand management and two identified the process with the corporate marketing programme. The international corporate identity group (ICIG) argue “...Corporate identity differs from traditional brand marketing since it is concerned with all of an organization's stakeholders and the multi-faceted way in which an organization communicates" (Balmer, 2001:284). A well-managed corporate identity leads to a strong corporate brand, according to Bick et al. (2003).

Even though eight of the 14 interviewees defined corporate identity as the visual communication, only two of the interviewees defined CIM as management of visual representation. Since each of the concepts had multiple definitions, it is clear that there was confusion about the meaning of these intangible concepts among the interviewees. This is consistent with Moingeon and Ramanantsoa's (1997) and Balmer's (2001) views that there is unclear and multi-defined use of the terminology. There were varieties of definitions among the managers working for the same company. It was not possible to identify a typical pattern of definitions for either marketing or human resource managers. However, several human resources managers initially claimed that they were the wrong person to interview since they perceived CIM as a pure marketing issue. One of the interviewed human resources managers initially claimed that such academic concepts are not used within the company. The findings support Proposition 1.

The interviewees were then asked if their respective company had a formal CIM process. The answers fell within the following three categories of answers: First, we do not have a formal strategic process that we call CIM but the company's communication and behaviour is based on corporate strategy, core values, internal policies/guidelines, organisational structure and/or pre-determined systems and processes. Second, we have a formal strategic process that we call CIM. It is based on corporate strategy, core values and internal policies/guidelines, organisational structure, and includes all corporate communication and behaviour. Third, we have a formal strategic process that we don't call CIM. It includes the guidelines for our visual communication.

The managers of four companies claimed to have a formal CIM process within their companies. The managers of one of these companies included only visual communication in the process, while the managers of the other three companies included all corporate communication and behaviour. The managers of the four companies who claimed not to have a formal process of CIM said that their companies' communication and behaviour was based on corporate strategy, core values, internal policies/guidelines, organisational structures and/or pre-determined systems and processes. The managers within those four companies agreed that even though they do not call their strategic process CIM, they unconsciously manage their corporate identity.

\section{Proposition 2: A CIM process that is initiated and controlled by top management is more likely to become effective.}

Respondents were asked where the responsibility of CIM was situated within the interviewed companies. The answers were divided between: Answer 1: Initiation and control is within the different departments, and Answer 2: Initiation and control is carried out by top management. Only two interviewees, both working within the same company, answered that different departments were responsible for the initiation and control of different parts of the process. The C.E.O. of that company stated, however, that if it had an image problem, then top management would probably initiate a change with input from all departments and individuals, but that so far there had not been a significant image or identity problem that would need to be controlled by the top management.

The answers from the other 12 interviewees correspond with Cunnington's (1996) and Van Riel and Balmer's (1997) views that the control of the CIM process should be in the hands of the top management. Nine of the interviewees mentioned that it was important that the C.E.O had the ultimate control of and interest in the CIM process.

Only the marketing director in the sixth company gave a clear statement of why the control should be at topmanagement level. He explained that it was very important for the reliability and the execution of the process that control was to be carried out from the top. He further claimed that it would otherwise be difficult to get budgets for the different programmes and that the staff would not take the CIM process seriously.

The human resource directors of the third and the eighth companies pointed out that it was very important that top management set the example and follow internal rules and policies. This is in line with Schein's (1985) argument that employees often imitate the behaviours and decisions of their leaders. Hatch and Schultz (1997) argue that it is important that managers are aware of their symbolic self and understand how others perceive them and their organisations within the cultural context, since their actions and 
statements simultaneously affect both the corporate identity and image. The answers support proposition two.

\section{Proposition 3: A CIM process that is integrated within the whole organisation and strives for consistency in communications with and behaviour towards the stakeholders is more likely to become effective.}

The next part of the interview investigated whether consistency in communication and behaviour was an important part of the CIM process. There was agreement among all the interviewees that consistency in communications and behaviours was important for their companies. The Human Resources Manager in company 5 mentioned two reasons for the importance of consistency in communication and behaviour towards stakeholders. She said that the clients recognise a company through consistency and know in advance what to expect when they approach the company, which, she argued, creates loyalty for the company. She also mentioned internal efficiency as a positive result of consistency in communication and behaviour, since the employees know what procedures and policies to follow. The M.D. in the eighth company mentioned: "If there is no consistency in communication, it gives schizophrenic messages, which brings distrust, since people would not know what to expect anymore." The H.R.D in the seventh company and the M.D in the sixth company explained that since people understand and view things differently, it is an internal challenge for companies to reach consistency in communication and behaviour.

Interviewees were asked if and how the CIM process was integrated within their companies. All the interviewees gave examples of channels and methods of integration: Internal communication, e.g. intranet, newsletters, meetings, road shows, etc; Staff training and development; Crossdepartmental involvement of the CIM process; Buy-in / involvement from staff, e.g. focus groups, and workshops. Rewarding successful internal behaviour; Manuals, guidelines; Top management living the example of preferred identity; Internal transparency of information; Informal communication / easy access to decision makers; Recruiting the "right" staff that fit in; and Decision makers agreeing beforehand on how and what to communicate so that they focus on the same things.

The findings show that, according to the interviewees, all the companies make some effort to integrate corporate identity into their companies. Three interviewed managers, the H.R.D and I.M. in the third company and the H.R.D. in the seventh company, explained that managers telling or dictating behaviour internally does not work for creating behavioural changes. They suggested that it was important to involve staff and to ensure that they understand the policy, value system, culture, etc, as well as why it exists and what it actually means.

Most of the interviewees said that their companies focused the CIM process mainly on communication and behaviour towards the employees and the customers. Some of the interviewees, however, also mentioned other stakeholders as important to include in the CIM process: strategic partners, unions, owners/shareholders, suppliers, etc. The H.R.D. in the third company explained that this company had developed codes of conduct for dealing with the unions, suppliers and partners. The purpose of these was to avoid power games and unhealthy discussions. The codes of conduct were based on buy-in and acceptance from the stakeholders. Several of the interviewees mentioned that their companies chose their strategic partners very carefully so that they and their offerings fitted in with the company's values and identity.

The findings indicate that all the interviewees believe that a CIM process that is integrated within the whole organisation and strives for consistency in communication and behaviour towards the stakeholders is to be preferred. This finding is supported by He and Balmer (2007) who stated that there has been a degree of convergence among marketing and organisational behaviour scholars in relation to identity studies. The first convergence can be seen with regard to the mutual recognition of the marketing and organisational behaviour approaches to identity studies. The findings support Proposition 3.

\section{Proposition 4: A CIM process that is adaptive is more likely to become effective.}

Respondents were asked if they believed that an adaptive CIM process was to be preferred. The answers were: Answer 1: Continuous adaptation is necessary. Answer 2: Changes of core values never take place but changes of logo and / or policies occur frequently.

The findings show that all the interviewed managers believed that an adaptive process is necessary, which is in line with Barich and Kotler's (1991), Van Riel and Balmer's (1997) and Bick et al's (2003) arguments. All the interviewed managers gave examples of what channels they used to identify whether changes were needed: Mystery guest / shopper programmes; Customer / market surveys; Image / brand tracking surveys; Informal feedback from staff; Feedback from staff through formal channels (meetings, workshops, focus groups, etc); Internal surveys (organisational perception studies, climate audits, management appraisals, staff satisfaction studies, etc); Feedback from external stakeholders other than customers; Trust of gut feeling; Following global trends and developments within the business; Toll-free customer care number; and Evaluation of PR / publicity. Van Riel and Balmer (1997) give a few examples of methods for revealing the actual corporate identity: Surveys; Semistructured interviews; Observation; Ethnography; Heuristic analyses of historical sources and conflicts; Examination of organisational documentation; Visual audits; and Group discussions.

Suggestions came up among the interviewees that adaptation of the CIM process should happen when trends, habits and demands change among the stakeholders; development movements happen within the business; image issues are identified; any of the internal values, policies, processes, etc does not work efficiently; and a better way of doing something is discovered. The findings support Proposition 4. 


\section{Proposition 5: A CIM process increases a company's competitiveness.}

Respondents were asked whether they believed that a CIM process increases a company's competitiveness. Four different categories of answers were identified: Answer 1: The company would not survive without CIM. Answer 2: The organisation would lose business without a strong identity. Answer 3: Without a clear and differentiated identity and a positive corporate brand, the company would be meaningless both internally and externally. Answer 4: The company has strong sub-brands, which are more important than the corporate brand; From a customer perspective the corporate identity is therefore not as important for us as if our business were based on one concept but when it comes to recruiting and motivating staff it is a competitive advantage to have a strong corporate brand.

All of the answers show that the interviewees believed that a CIM process increases a company's competitiveness even though one of the interviewees appeared slightly doubtful. Four of the 14 interviewees believed that the company would not survive without CIM, while eight argued that some of the business would be lost. One of the interviewees highlighted that a lack of CIM would make the company meaningless internally as well as externally. Only one of the interviewees perceived CIM as less important from a customer perspective, but he highlighted the importance of a strong corporate identity regarding staff recruitment and retention.

The reasons given for why a CIM process increases a company's competitiveness were: Policies are built on experiences of what works well; CIM creates loyalty, trust and top-of-mind awareness; The immediate competitors have a very strong corporate identity; Stakeholders would not know "who" the company is, what the company stands for and what to expect without CIM; Without a CIM process it would not be possible to create a strong corporate brand; Without a CIM process the messages would not stand for anything else than a "schizo" business; Without a CIM process, it would be an uninteresting "me-too" brand; If you cannot deliver in accordance with the expectations you have built up, then you definitely lose customers to your competitors; and If the "right persons" are recruited and retained, they will stand for and live up to the values, which will lead to better offerings. The findings support Proposition 5.

\section{Recommendations}

There is a very clear view, both among the literature specialists and among the 14 managers who are represented in this research that an effective and well-managed CIM process leads to competitive advantage for a company. It is therefore strongly recommended for companies that have the vision of becoming successful within their business area to invest resources, time as well as money, in a strategic CIM process.

The CIM process should be initiated and controlled by top management, with the C.E.O having the ultimate control and interest in the process and decisions regarding the CIM process being taken in the board room; There must be buyin from the staff as well as from the external stakeholders; companies should aim for consistency in all communication, behaviour and symbolism for all the different stakeholders; the development of corporate values, policies/guidelines, organisational structure and systems/processes that stimulate the implementation of a visionary corporate identity should be included; it must be implemented throughout the whole organisation on the basis of involvement and understanding rather than through dictation; and it must be adaptive and open to internal and environmental changes.

We suggest a step-by-step management guide on how to reach an effective and successful corporate identity. This is shown in Figure 1.

Step 1 - Create a Visionary Corporate Identity

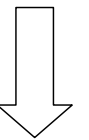

Step 2 - Communicate the visionary corporate iden ity internally and kick-off projects.

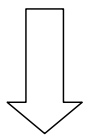

Step 3 - Decide what channels and methods to use for researching the status of the corporate identity and the corporate image.

Step 4 - Implement the visionary corporate identity internally.

Figure 1: Developing a corporate identity management
process

The purpose of the first step is to decide what the ideal corporate identity would be for the company. Top management should initiate buy-in from all the important stakeholders. Step 2 includes starting internal projects to develop the following: Core values; internal policies and guidelines for corporate behaviour and communications; interlinked systems and processes; and an organisational structure. All of these projects should support the development of the visionary corporate identity. The projects should be initiated and controlled by top management; include representatives from all departments; include buy-in and involvement from all levels of the organisation and, if relevant, also involvement and buy-in from external stakeholders; and aim to keep the result simple and adaptive so that it will be easy to live up to and 
easy to change when necessary. The purpose of the third step is to ensure that the process is adaptive to, for example, changes in trends, habits and demands among the stakeholders; the development movements within the business area; image issues and ineffective policies and processes that need to be changed; the discovery of better ways of doing things and changed laws. The ultimate goal is that: the visionary identity $=$ the real identity $=$ the image $=$ reputation. Suggestions of channels and methods to use include the following: Mystery guest or shopper programmes; Customer and market surveys; Image and brand tracking surveys; Informal feedback from staff; Feedback from staff through formal channels; Internal surveys; Feedback from external stakeholders other than customers; Trust of gut feeling; Follow global trends and developments; Toll free customer care numbers; and the evaluation of publicity. The channels or methods to use, what to measure/research and the frequency of each method should be decided upon during this step. Step four is to motivate the staff to start "living" the visionary corporate identity. The implementation should be led by top management and include a two-way communication process based on involvement and understanding. This should be an ongoing process rather than a once-off step. Suggested methods of implementation include: Staff training and development; Road shows; Workshops on the Intranet; Internal newsletters; Rewarding successful internal behaviour; Top management living example of the preferred identity; Recruiting the "right" staff and strategic partners that fit in. The management of the organisation's corporate identity will go a long way to help various stakeholders form images of the firm and in the long run an enduring reputation.

\section{References}

Aaker, D. 2004. 'Leveraging the corporate brand', California Management Review, 46 (3), 6-18.

Abratt, R. 1989. 'A new approach to the corporate image management process', Journal of Marketing Management, 5 (1), 63-76.

Ackerman, L. D. 1983. 'How to make corporate identity work harder for the organisation', Management Review, 72 (1), 38-44.

Albert, S. \& Whetten, D. A. 1985. 'Organizational identity’, Research in Organizational Behaviour, 7, 263-295.

Balmer, J. M. T. \& Gray, E. R. 1999. 'Corporate identity and corporate communications: creating a competitive advantage', Corporate Communications: An International Journal, 4 (4):171-177.

Balmer, J. M. T. 2001. 'Corporate identity, corporate branding and corporate marketing - Seeing through the fog', European Journal of Marketing, 35 (4):248-291.

Bendixen, M. \& Abratt, R. 2007. 'Corporate identity, ethics and reputation in supplier-buyer relationships,' Journal of Business Ethics, 76:69-82.
Barich, H. \& Kotler, P. 1991. 'A framework for marketing image management’, Sloan Management Review, 14:20-39.

Bernstein, D. 1986. Company image and reality: A critique of corporate communications. $3^{\text {rd }}$ Edition. Eastbourne: Holt, Rinehart \& Winston.

Berrone, P., Surroca, J. \& Tribo, J. A. 2007. 'Corporate ethical identity as a determinant of firm performance: A test of the mediating role of stakeholder satisfaction', Journal of Business Ethics, 76:35-53.

Bick, G., Jacobson, M. C. \& Abratt, R. 2003. 'The corporate identity management process revisited, Journal of Marketing Management, 19:835-855.

Bickerton, D. 2000. 'Corporate reputation versus corporate branding: the realist debate', Corporate Communication: An International Journal, 5 (1):42-48.

Carroll, C. E. 2002. 'Case Study', Journal of Organizational Change Management, 15(6):556-562.

Cunnington, B. 1996. 'The marketing learning identity', Journal of Consumer Marketing, 13 (5):56-65.

Dowling, G. R. 1986. 'Managing your corporate images', Industrial Marketing Management, 15:109-115.

Ettenson, R. \& Knowles, J. 2008. 'Don't confuse reputation with brand,' Sloan Management Review, 49(20):19-21.

Falconer, D. J. \& Mackay, D.R. 1999. 'The key to the mixed method dilemma'. $10^{\text {th }}$ Australasian Conference on Information Systems, Victoria University of Wellington, New Zealand, 1-3 December.

Fombrun, C. \& Shanley, M. 1990. 'What's in a name? Reputation building and corporate strategy', Academy of Management Journal, 33(20):233-258.

Fombrun, C. \& Van Riel , C. B. M. 2004. Fame \& fortune: How successful companies build winning reputations. London, UK: Pearson Financial Times.

Gioia, D. A. 2000. 'Organisational identity, image and adaptive instability', Academy of Management Review, 25(1):63-82.

Hatch, M. J. \& Schultz, M. 1997. 'Relations between organizational culture, identity and image', European Journal of Marketing, 31(5/6):356-366.

Hatch, M. J. \& Schultz, M. 2003. 'Bringing the corporation into corporate branding', European Journal of Marketing, 37(7/8):1041-1064.

He, H. W. \& Balmer, J.M.T. 2007. 'Identity studies: multiple perspectives and implications for corporate-level marketing', European Journal of Marketing, 41(7/8):765785. 
Moingeon, B. \& Ramanantsoa, B. 1997. 'Understanding corporate identity: the French school of thought', European Journal of Marketing, 31(5):383-395.

Mukherjee, A. \& He, H. 2008. 'Company identity and marketing: an integrative framework', Journal of Marketing Theory and Practice, 16(2):111-126.

Schein, E. H. 1985. Organisational culture and leadership. San Francisco: Jossey-Bass Inc. Publishers.

Van Riel, C. B. M. \& Balmer, J.M.T. 1997. 'Corporate identity: the concept, its measurement and management', European Journal of Marketing, 31(5):340-355. 